\title{
GIST DEL TABIQUE RECTOVAGINAL
}

\author{
Lima Pinto F, Martínez Alegre J \\ Hospital Universitario Infanta Sofía, San Sebastián de los Reyes-Madrid.
}

\section{CASO CLÍNICO}

Presentamos el caso de una mujer de 59 años, sin antecedentes de interés, que consulta por proctalgia, sensación de peso perineal y prolapso hemorroidal. Al tacto rectal se palpó una masa en cara anterior, submucosa, de consistencia elástica, con impronta vaginal, a 3-4cm del margen anal. Se realizaron ecoendoanal, TC (Figura 1ig 1) y RMN hallándose masa en espacio rectovaginal de $7,5 \times 5 \mathrm{~cm}$ sin plano de separación con pared posterior uterina, recto ni sacos vaginales. Con una BAG se confirmó que correspondía a un GIST extraintestinal. Presentada en comité de tumores para valoración multidisciplinaria: se determina, ante la elevada morbimortalidad y alta agresividad quirúrgica para conseguir resección (R0), inicio neoadyuvancia con mesilato de imatinib (400mg día, 4 meses). Reevaluación mediante PET-TC y RMN (Figura 2) con buena respuesta terapéutica. Se realiza tratamiento quirúrgico, vía transperineal, consiguiendo enucleación completa (Figuras 3 y 4). Anatomía Patológica confirmó la presencia de un GIST del tabique rectovaginal con cambios secundarios a tratamiento (áreas de hemorragia y esclerosis). El postoperatorio transcurrió sin complicaciones.

Ante un tumor del espacio rectovaginal hay que tener en mente la existencia de los GIST (1). El diagnóstico preoperatorio, con pruebas de imagen y biopsia (2), es importante para realizar una terapéutica adecuada y multidisciplinaria con un máximo beneficio y una mínima agresión, como en nuestro caso fue el abordaje transperineal. Se puede valorar la posibilidad de neoadyuvancia (3), en casos seleccionados, para conseguir resecciones con criterios de radicalidad $(\mathrm{R} 0)$. 


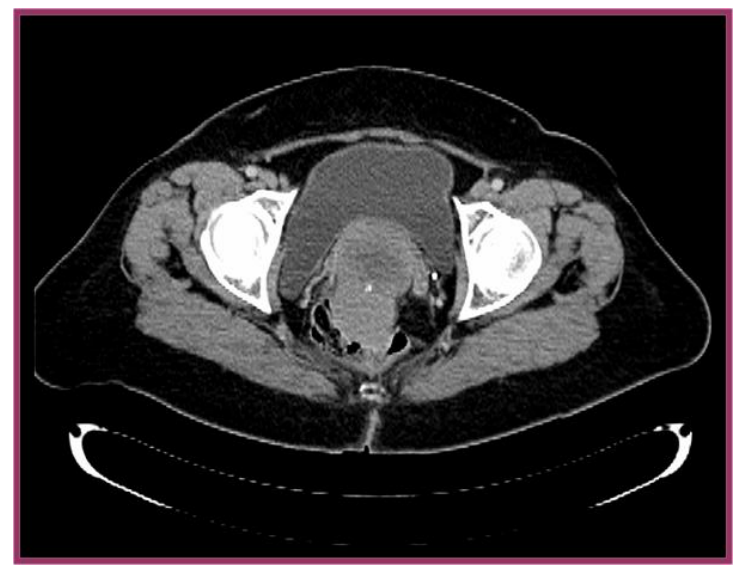

Figura 1: TC preneoadyuvancia: Masa en espacio rectovaginal de $7,5 \times 5 \mathrm{~cm}$ sin plano de separación con pared posterior uterina, recto ni vagina

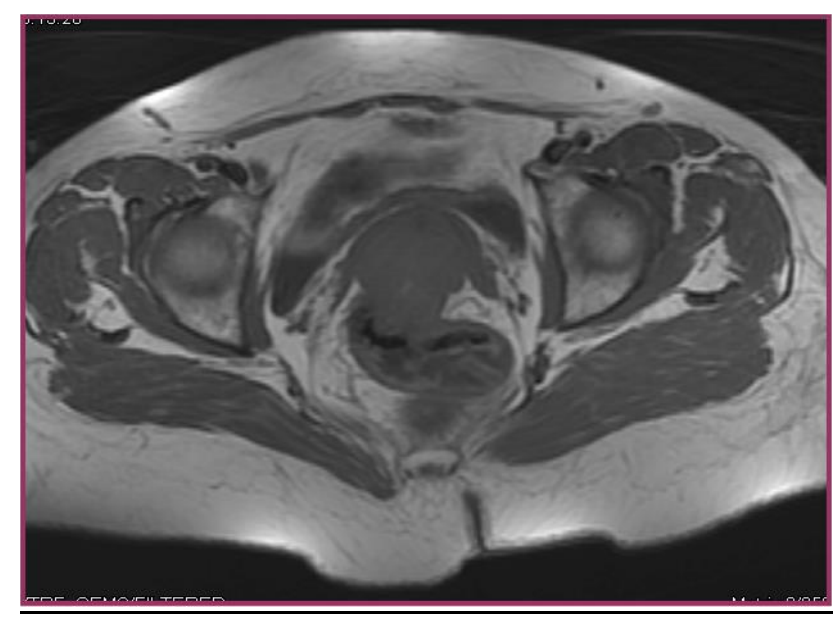

Figura 2: RMN postneoadyuvancia: que pone de manifiesto la buena respuesta terapéutica con disminución del tamaño tumoral y plano de separación de órganos vecinos. 

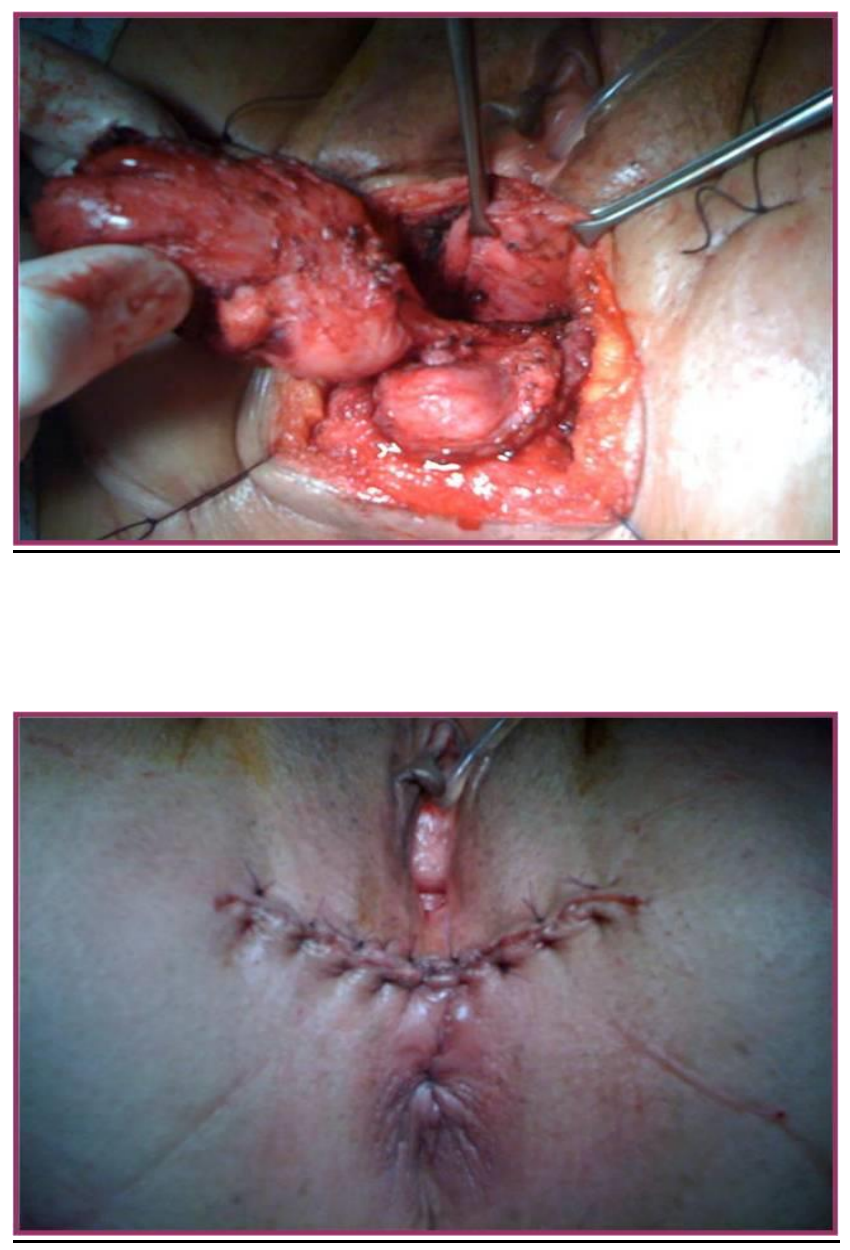

Figuras 3 y 4: abordaje quirúrgico transperineal, incisión horizontal, con resección completa tumoral, consiguiendo buen plano de disección sin lesión rectal ni de la pared vaginal.

\section{BIBLIOGRAFÍA:}

1. Lee YH; Chong, GO; Hong, DG. "Is gastrointestinal stromal tumor (gist) originating from the rectovaginal septum gist or extra-gist (egist)? A case report with literature review." Eur J Gynaecol Oncol. 2015; 36(6):750-4.

2. Sanmartín JM, Román Sánchez MJ, Esteve Fuster N, Saco López A, Piñero Sánchez OC, Candela Hidalgo MA, López Fernández JA, Muci Añazco T, Martínez Escoriza JC. Tumor del estroma gastrointestinal en el tabique rectovaginal, un desafío diagnóstico. "Gastrointestinal stromal tumor of the rectovaginal septum: a diagnostic challenge." Prog Obstet Ginecol 2010; 53:288-91. 
3. Bannura C G, Gallardo M C, Cornejo C V. Neoadyuvancia con imatinib en el manejo de gist gigante del tabique rectovaginal- "Neo-adjuvant treatment with imatinib for a rectal gastrointestinal stromal tumor" Rev Chil 2014;66-2. 